\title{
Evaluation of the possible therapeutic role of omega-3 on ankle joint and lung in a model of rheumatoid arthritis in rats: A histological and immunohistochemical study
}

\author{
Original \\ Article \\ Mona H. Raafat', Ghada Galal Hamam ${ }^{1}$, Maha S. Farhan', Laura M. Sabbagh', \\ Nour M. Abeduldaem ${ }^{2}$ and Abdulghani M. Sharaf ${ }^{2}$ \\ Department of Histology and Cell Biology, ${ }^{l}$ Undergraduate ${ }^{2}$, Faculty of Medicine, Ain Shams \\ University, Cairo, Egypt
}

\begin{abstract}
Introduction: Rheumatoid arthritis (RA) is a chronic inflammatory systemic autoimmune disease. Lung disease has been recognized as a common complication of RA. Omega-3 is an essential fatty acid with wide range of activity.

Aim of the work: To investigate the possible therapeutic role of omega-3 free fatty acid on the structure of ankle joint and lung in a model of adjuvant-induced RA in rats.

Materials and Methods: Thirty adult male albino rats were divided into three groups; Group I served as a control group. Group II was used as a model of RA. Rats of this group were given single subcutaneous injection of $0.1 \mathrm{ml}$ of complete Freund adjuvant in their hind paws. Group III (omega 3-treated group), omega-3 was given in as a dose of $300 \mathrm{mg} / \mathrm{kg}$ orally administered after two weeks of RA induction and continued daily for another two weeks. The ankle joint and the lungs from all groups were dissected out after two and four weeks and processed for light microscopic examination. Histomorphometric studies and statistical analysis were also done.

Results: RA was confirmed histologically in the ankle joint after two weeks and was aggravated after four weeks. Erosion of articular cartilage and mononuclear cellular infiltration in the synovium were noticed in both time points. Moreover, the lungs after two weeks showed focal inflammatory cellular infiltration and pulmonary fibrosis that were more evident after four weeks of untreated RA. This was associated with significant increase in the mean area percentage of collagen fibers and number of cells positive for TNF- $\alpha$ immunohistochemical reaction compared to the control group. Omega- 3 treated group illustrated improvement of both ankle and lung structures.

Conclusion: Omega-3 significantly ameliorated the structural damage of ankle joint and lung after RA induction.
\end{abstract}

Received: 02 April 2018, Accepted: 15 June 2018

Key Words: Histology, lung, omega-3, rats, rheumatoid arthritis.

Corresponding Author: Mona H. Raafat, Department of Histology and Cell Biology, Faculty of Medicine, Ain-Shams University, Cairo, Egypt, Tel.: 0201005223587, E-mail: raafat.mona@yahoo.com.

ISSN: 1110-0559, Vol. 41, No. 3

\section{INTRODUCTION}

Rheumatoid arthritis (RA) is a common autoimmune disease $^{[1]}$ affecting about $0.05-1 \%$ of the human population worldwide ${ }^{[2]}$, with $0.2 \%$ prevalence in $\operatorname{Egypt}^{[3]}$. The number of patients suffering from RA worldwide is expected to increase from 46 million in 2005 to 65 million in $2030^{[4]}$. It induces a massive burden on health services worldwide ${ }^{[2]}$. It is often associated with chronic disability, early mortality, systemic complications, and it has a high socioeconomic burden on whole society ${ }^{[1]}$.

Although joint disease is the most common presentation of RA, there are many extra-articular manifestations including subcutaneous nodule formation, vasculitis, inflammatory eye disease and lung disease. Of these manifestations, lung disease is a major contributor to morbidity and mortality. In some cases, respiratory symptoms may precede articular symptoms. Pulmonary complications account for 10 to $20 \%$ of mortality in RA patients. The pleura and the airways, as well as the interstitium and vasculature of the lung can be affected ${ }^{[5]}$. Progression of parenchymal lung disease results in impaired oxygen transfer and scarring within the lungs ${ }^{[6]}$.

Lung fibrosis that complicates RA is treated with corticosteroids together with cytotoxic agents which have numerous side effects. The anti-fibrotic efficacy of immunosuppressive agents is limited, and the results of long term survival rates are extremely poor with the current therapeutic approaches. Currently, the only effective treatment available for progressive lung fibrosis is lung transplantation. Therefore, new drugs are needed with better efficacy and tolerability for pulmonary fibrosis that complicates $\mathrm{RA}^{[7]}$. Recently, researchers are directed towards traditional system of medicine for the discovery 
of drugs with minimal side effects ${ }^{[8,9]}$. Furthermore, over the past several years evidence has been growing on the benefits of dietary fats on bone health. It was also reported that some dietary supplements, as n-3 polyunsaturated fatty acid, can be involved in bone metabolism ${ }^{[9,10]}$.

Omega-3 fatty acids are a group of poly-unsaturated fatty acids with multiple double bonds. It is mainly gained from seafood consumption ${ }^{[10,11]}$. Omega-3 fatty acids are essential fatty acids that cannot be manufactured by the body, consequently, they must be obtained from food or taken as supplements. They are found mainly in fish oils (salmon and tuna fish), canola oil and walnuts ${ }^{[12]}$. They have long been known to possess a wide range of beneficial effects, including the treatment of various forms of chronic inflammatory diseases ${ }^{[11]}$.

Hence, in the present study we hypothesized that supplementation with omega-3 free fatty acid might be a valuable therapeutic approach to improve histological structure of ankle joint and lung in a rat model of adjuvant induced RA.

\section{MATERIALS AND METHODS}

The experiment was conducted on thirty adult male albino rats weighing 170-200 gm. Animals were purchased from animal house, Faculty of Medicine, Ain shams University. They were housed in clean wire mesh cages and had free access to standard chow diet and tap water in the scientific research center, Faculty of Medicine, Ain Shams University. All the experimental procedures were carried out according to the recommendation and the guidelines of the institutional animal ethics committee at Faculty of Medicine, Ain Shams University. Animals were carefully selected free from: gait disorders, swollen joints or limps. After seven days of acclimatization, animals were randomly divided into three main groups:

Group I: (Control group): This group was further subdivided into two subgroups six animals each: Subgroup Ia: received a single subcutaneous injection of $0.2 \mathrm{ml}$ normal physiological saline $(0.9 \%$ sodium chloride $)$ [which was the solvent of complete Freund's adjuvant (CFA)] in the metatarsal footpad of left hind paw using insulin syringe (Ameco, Egypt, Tenth of Ramadan City, Egypt) in day zero of the experiment. Animals were then divided equally to be sacrificed after two and four weeks from the injection. Subgroup Ib (Omega-3 group): Rats of this subgroup received single subcutaneous injection of normal saline in the same site and dose as in subgroup Ia. After two weeks, they were given $300 \mathrm{mg}$ omega-3/kg orally once daily by intragastric tube ${ }^{[13]}$, and then they were sacrificed after further two weeks.

Group II: (RA group): It included twelve rats. Arthritis was induced in rats of this group by single subcutaneous injection of $0.1 \mathrm{ml}$ of CFA suspended in $0.2 \mathrm{ml}$ normal saline in the metatarsal footpad of left hind limb using $1 \mathrm{ml}$ insulin syringe ${ }^{[14]}$. The day of injection was considered day zero. Rats were then divided into two subgroups six animals each: Subgroup IIa (early RA): rats were left without any treatment then they were sacrificed after two weeks from the injection of CFA. Subgroup IIb (late RA): rats were left without any treatment then they were sacrificed after four weeks from the injection.

Complete Freund's adjuvant (Sigma- Aldrich, St. Louis, MO, USA) was purchased as non-metabolizable oils (paraffin oil and mannide monooleate) containing $1 \mathrm{mg} / \mathrm{ml}$ heat-killed and dried Mycobacterium tuberculosis.

Group III: (Omega-3 treated group): This group included six rats. After induction of arthritis as in group II, rats of this group were left without treatment for two weeks. Then they were treated with $300 \mathrm{mg}$ omega-3/ $\mathrm{kg}$ once daily orally by intragastric tube for further two weeks ${ }^{[13]}$, and then they were sacrificed (i.e. after four weeks from the beginning of the experiment).

Omega-3 used in this study was in the form of gelatinous capsules containing $1 \mathrm{ml}$ omega- 3 fatty acids in the form of fish oil (Kirkland signature dietary supplements). Each capsule was evacuated carefully by $1 \mathrm{ml}$ insulin syringe and was given to rats at a dose of $300 \mathrm{mg} / \mathrm{kg}$ (equivalent to $0.02 \mathrm{ml}$ fish oil /rat) once daily by an intra-gastric tube ${ }^{[15]}$.

All injections were preceded by sterilization of the skin of left hind paw with Betadine antiseptic solution.

\section{Histological assessment:}

\section{Sample collection and preparation:}

Animals were sacrificed after ether inhlation at the aprpopriate time.

\section{1-The ankle joint}

The right hind limb was dissected, trimmed of skin and muscles, digits were removed, and ankles were fixed in $10 \%$ buffered formalin for two days. Decalcification was done in the chelating agent ethylene diamine tetra acetic acid (EDTA) (5.5 g EDTA in $90 \mathrm{ml}$ distilled water and $10 \mathrm{ml}$ formaldehyde $37-40 \%$ ) for one month. EDTA was renewed every two days until the specimens were completely soft and decalcified. The ankle joints were cut longitudinally in a sagittal plane along the central line. Specimens were then dehydrated, cleared, and embedded in paraffin. Sectioning was done at five $\mu \mathrm{m}$ thickness with subsequent staining with $H \& E^{[16]}$.

\section{2-The Lung}

Thoracotomy was done by lifting the sternum and cutting the ribs on both sides at their attachment to the costal cartilage. Intratracheal instillation of $0.5 \mathrm{ml} 10 \%$ formalin was done till the lungs fill the chest cavity ${ }^{[17]}$. The upper lobe of both lungs was taken and fixed immediately 
in $10 \%$ formol saline solution and were then processed to obtain paraffin sections of five $\mu \mathrm{m}$ thickness. Sections were subjected to H\&E stain and Mallory's triple stain ${ }^{[16]}$. Other sections were cut on positively charges slides and were stained with avidin-biotin peroxidase for demonstration of inflammatory cells immunoreacted to tumor necrosis factor-alpha (TNF- $\alpha$ ) then the sections were counterstained with $\mathrm{Hx}^{[16]}$. Polyclonal antibody against TNF- $\alpha$ (dilution 1:100) was purchased from R\&D Systems (Minneapolis, Minnesota, USA). Positive reaction appeared as brown cytoplasmic reaction. Negative control was done by omitting the step of primary antibody, and positive control was done by using thymus tissue section.

\section{Morphometric study and statistical analysis}

Specimens of the lungs were analyzed using an image Leica Q win V.3 program installed on a computer in the Histology and Cell biology Department, Faculty of Medicine, Ain Shams University. The computer was connected to a Leica DM2500 microscope with built-in camera (Leica Microsystems GmbH, Ernst-Leitz-StraBe, Wetzlar, Germany). Ten specimens from six different rats of each subgroup were examined $(n=10)$. From each specimen, five different captured non-overlapping fields were taken. Five different readings from every captured photo were counted and the mean was calculated for each specimen. Measurements were taken by an independent observer blinded to the specimens' details to perform an unprejudiced assessment.

\section{The following parameters were measured:}

(1) The mean of area percentage of collagen fibers using Mallory trichrome stain.

(2) The mean count of (TNF- $\alpha$ ) positive brownish cells

All the measurements were taken at high-power fields of magnification $(\times 400)$.

\section{Statistical analysis}

All data were collected, revised, and subjected to statistical analysis using one-way analysis of variance performed with SPSS.21 program (IBM Inc., Chicago, Illinois, USA) analysis for variance (ANOVA)-one way analysis and post-Hoc least significant difference (LSD). The significance of the data was determined by the $\mathrm{P}$ value. $P$ values greater than 0.05 were considered non-significant, and $\mathrm{P}$ values less than 0.05 were considered significant. Summary of the data was expressed as mean + standard deviation (SD).

\section{RESULTS}

\section{Gross observation and gait}

Injection of CFA into the footpad of the left hind paw resulted in an initial acute inflammation, redness and swelling that appeared on the ipsilateral paw on the same day of the injection and persisted for 10 days (Figs.1a and $1 \mathrm{~b}$ ). This was followed by a chronic polyarthritic phase involving the other three paws, which started on day 10 and persisted for the entire period of the experiment.

Gait was checked visually. In RA group, all the animals were limping and inactive starting four days after injection. In omega-3 treated rats the gait was minimally affected.

\section{Histological results}

Subgroups of the control group showed nearly the same histological appearance in all studies performed.

\section{I-Ankle joint}

Histological examination of H\&E stained sections of control (group I) showed the ankle joint with its two surfaces (tibial and talus) separated by the joint cavity. On both side, bones were covered by hyaline cartilage (articular cartilage) with regular smooth surface lacking the covering perichondrium. The articular cartilage was formed of four zones: a superficial tangential zone contained elongated chondrocytes with their long axis parallel to the surface; a second middle zone (transitional zone) that contained scattered more rounded chondrocytes; a third zone (radial zone) having spherical chondrocytes arranged in a columnar manner perpendicular to the surface; and a fourth zone (calcified zone) with scattered chondrocytes bounded superiorly by tidemark line, then underneath the calcified zone there was the subchondral bone (Fig. 2). The synovial membrane was formed of intima and stroma. The intima was formed of macrophage-like synoviocyte type A and fibroblast-like synoviocyte type B while; the stroma was formed of fibro-adipose connective tissue containing collagen fibers, many adipocytes and few blood vessels (Fig. 3).

Examination of H\&E stained sections of early RA (subgroup IIa) showed irregular surface (erosions) of the articular cartilage with loss of its smooth contour. In addition, the tidemark line was faint in some areas while it was absent in other areas with absence of calcified cartilage. Empty lacunae and chondrocytes with pyknotic nuclei were also noticed (Fig. 4). The synovial membrane showed apparent increase in the number of macrophagelike synoviocyte type $\mathrm{A}$ and mononuclear cellular aggregations. Apparent increase in the collagen fibers between the adipocytes in the stroma was also noticed (Fig. 5).

Meanwhile, examination of H\&E stained sections of late RA (subgroup IIb) showed focal areas of destruction of articular cartilage while other areas showed an apparent decreased thickness of the articular cartilage compared to the control group with loss of basophilia and faint tidemark. Furthermore, degenerated chondrocytes with pyknotic nuclei and some empty chondrocytes' lacunae were frequently noticed. Areas of destruction of the 
underlying bone were also detected (Fig. 6). The synovial membrane showed focal disruption of the cells lining the intima. Mononuclear cellular infiltration was frequently noticed between dilated congested blood vessels in the stroma (Fig. 7).

Administration of Omega-3 fatty acids (group III) exerted an ameliorating effect on the joint structure after induction of arthritis. The articular cartilage appeared with basophilic matrix containing chondrocytes inside their lacunae with an apparent increased thickness compared to subgroup IIb. Nevertheless, few areas of the articular cartilage were still seen with slight irregularity of its surface (Fig. 8). Moreover, the synovial membrane showed mild increase in the intimal thickness (Fig. 9).

\section{II-Lung:}

Examination of H\&E-stained sections of control group showed the lung formed of alveoli separated by thin interalveolar septa, alveolar sacs, alveolar ducts, bronchioles, bronchi, and blood vessels. Alveoli and alveolar sacs were lined by two types of cells. Type-I pneumocytes were flat with flattened nuclei, and typeII pneumocytes were cuboidal with rounded nuclei. The bronchi were lined by pseudostratified columnar epithelium, which gradually decreased to become columnar and cubical in the small bronchioles. Lamina propria was seen under the epithelium. Bundles of smooth muscles and adventitia were also noticed surrounding the mucosa (Fig. 10).

Examination of H\&E stained sections of early RA (subgroup IIa) showed inflammatory cellular infiltration in the lung interstitium, lamina propria of the bronchi and surrounding the bronchi. Some alveoli were narrowed and blood vessels appeared congested with thickening of their wall. Eosinophilic exudates and extravasations of red blood cells in the inter-alveolar septa were frequently seen. Cellular debris was also noticed in the lumen of some bronchi (Figs.11, 12). Numerous goblet cells were seen in the lining of some bronchi (Fig. 12). While, examination of H\&E stained sections of late RA (subgroup IIb) showed thickened inter-alveolar septa with obliteration of most alveoli and dilatation of others. Inflammatory cellular infiltration and multinucleated giant cells were noticed in the lung interstitium (Fig. 13). However, some areas showed narrowing of some alveoli and dilatation of others. Whorly cellular acidophilic plugs were sometimes noticed (Fig. 14). Moreover, most bronchi showed areas of partial loss of the epithelial lining. Their wall was heavily infiltrated with inflammatory cells. Cellular debris and inflammatory cells could be also seen in their lumen (Fig. 15).

Alternatively, administration of Omega-3 fatty acids (group III) exerted an ameliorating effect on the lung structure. There were focal areas of thickened inter-alveolar septa with inflammatory cellular infiltration and apparent increase of the number of pneumocyte type II. Moreover, the lining epithelium of the bronchi was nearly comparable to that of the control group. While few inflammatory cells were noticed surrounding the bronchi (Figs. 16, 17)

In Mallory's trichrome-stained sections, few collagen fibers were seen in the interalveolar septa, in the lamina propria and adventitia surround the bronchi in the control group (Fig. 18). In early RA (subgroup IIa), many collagen fibers were seen in the lamina propria and around the wall of bronchi (Fig. 19). Meanwhile, sections of late RA (subgroup IIb) showed increased collagen fibers in the interalveolar septa as well as around the bronchi (Fig. 20). While, in group III some collagen fibers were seen in the interalveolar septa as well as around the wall of bronchi (Fig. 21). This was confirmed by the present histomorphometric results (Table1, Histogram 1).

In immnohistochemical analysis for TNF- $\alpha$, sections from the control group showed very few cells with positive immune reaction in the lumen of some alveoli (Fig. 22). However, in subgroup IIa some cells with positive immune reaction were seen in inter-alveolar septa (Fig. 23). Meanwhile, in subgroup IIb, many cells with positive TNF- $\alpha$ immune reaction were seen in the septa and inside the alveoli (Fig. 24). Whereas, sections of group III showed few cells with positive immune reaction for TNF- $\alpha$, in inter alveolar septa (Fig. 25). This was confirmed by the present histomorphometric results (Table1, Histogram 1).

\section{Histomorphometric results (table 1 and histogram 1):}

The mean area percentage of collagen fibers and the mean number of TNF- $\alpha$ positive cells in subgroup IIa showed a significant $(P<0.05)$ increase compared to control group. In subgroup IIb a significant increase was noticed compared to control group, subgroup IIa and group III. While group III showed a significant increase compared to control group and a significant decrease compared to subgroups IIa and IIb.

Table 1: Showing mean $\pm \mathrm{SD}$ of area percentage of collagen fibers and mean $\pm \mathrm{SD}$ of number of TNF- $\alpha$ positive cells / HPF in different groups

\begin{tabular}{lcc}
\hline Groups & Mean \pm SD of area \% of collagen fibers & Mean \pm SD of number of TNF- $\alpha$ positive cells \\
\hline Group I (control) & $6.36 \pm 1.59$ & $0.6 \pm 0.54$ \\
Subgroup IIa & $28.41 \pm 1^{*}$ & $27.6 \pm 2.3^{*}$ \\
Subgroup IIb & $36.84 \pm 2.15^{\mathbf{\Delta}}$ & $57.8 \pm 4.14^{\mathbf{\Delta}}$ \\
Group III & $20.13 \pm 1.31^{* \diamond}$ & $15.6 \pm 2.3^{* \bullet}$ \\
\hline
\end{tabular}




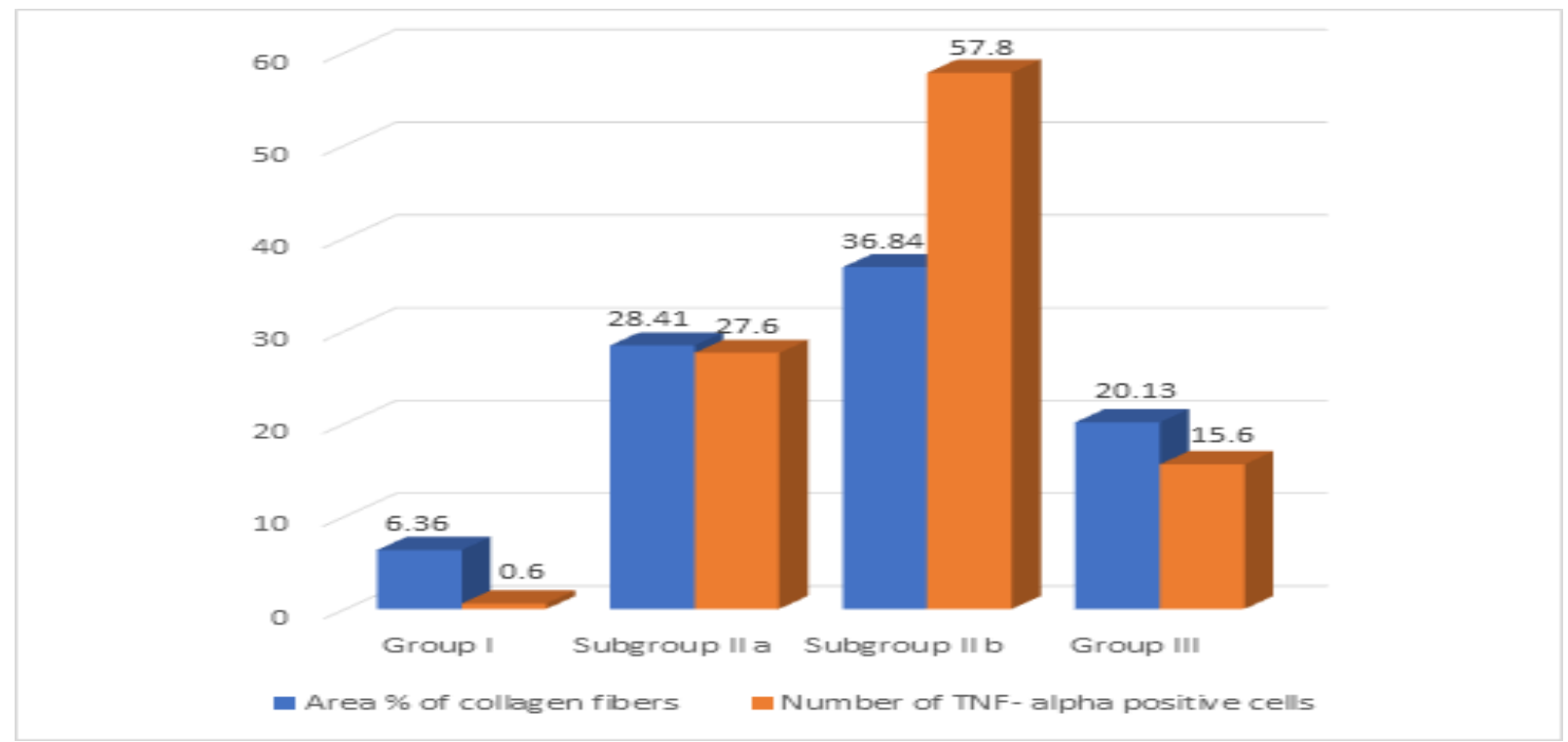

Histogram 1: Showing the mean of area percentage of collagen fibers and mean number of TNF- $\alpha$ positive cells/HPF in different groups.

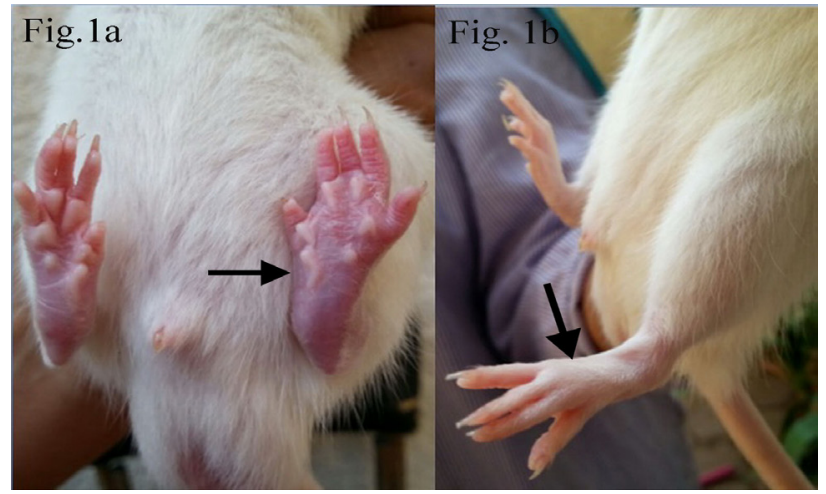

Fig. 1: Showing (a) Acute inflammation and swelling $(\uparrow)$ of the left hind paw on day one. (b) Swelling and deformity $(\uparrow)$ on day four.

Complete Freund's adjuvant treated groups

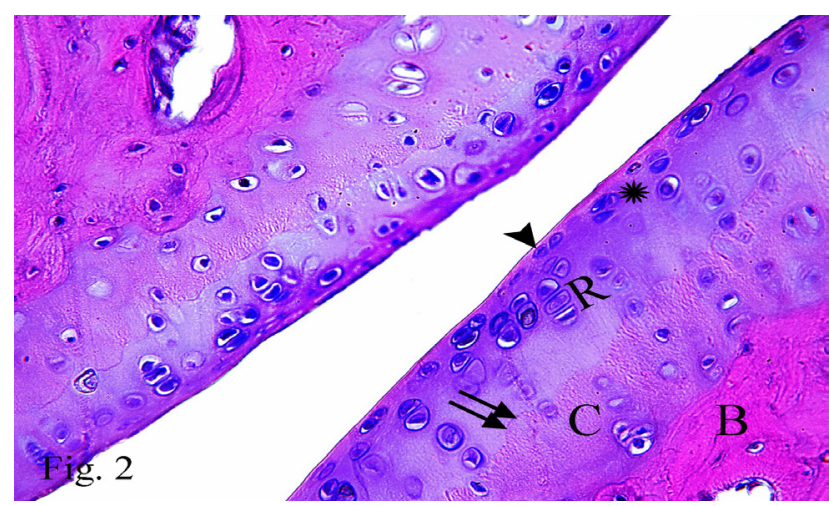

Fig. 2: Showing the four zones of the articular cartilage: a superficial tangential zone $(\boldsymbol{\Delta})$, transitional zone $(*)$ that contains scattered chondrocytes, radial zone (R) containing chondrocytes arranged perpendicular to the surface and the calcified cartilage zone $(\mathrm{C})$ bounded by tidemark line $(\uparrow \uparrow)$. Notice subchondral bone (B) underneath the calcified cartilage.

(Group I) H\&E × 400

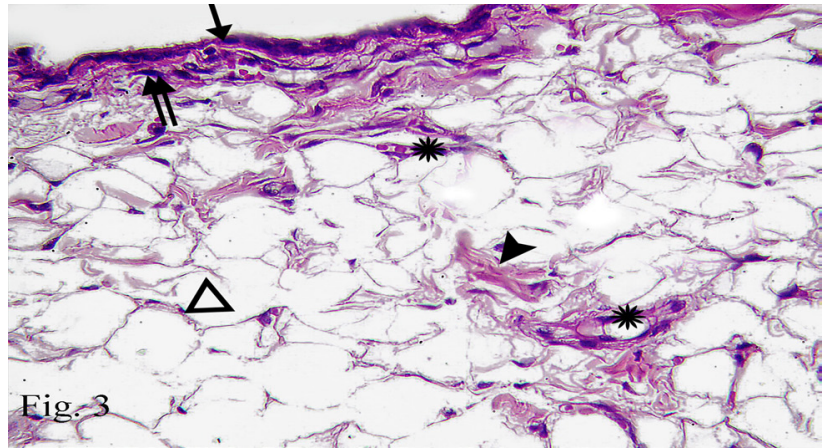

Fig. 3: Showing the synovial membrane composed of intima and stroma. The intima is formed of macrophage-like synoviocyte type A $(\uparrow)$ and fibroblast-like synoviocyte type B $(\uparrow \uparrow)$. The stroma is formed of fibro-adipose connective tissue containing collagen fibers $(\boldsymbol{\Delta})$ and many adipocytes $(\Delta)$. Blood capillaries $\left.{ }^{*}\right)$ are seen in the stroma.

(Group I) H\&E $\times 400$
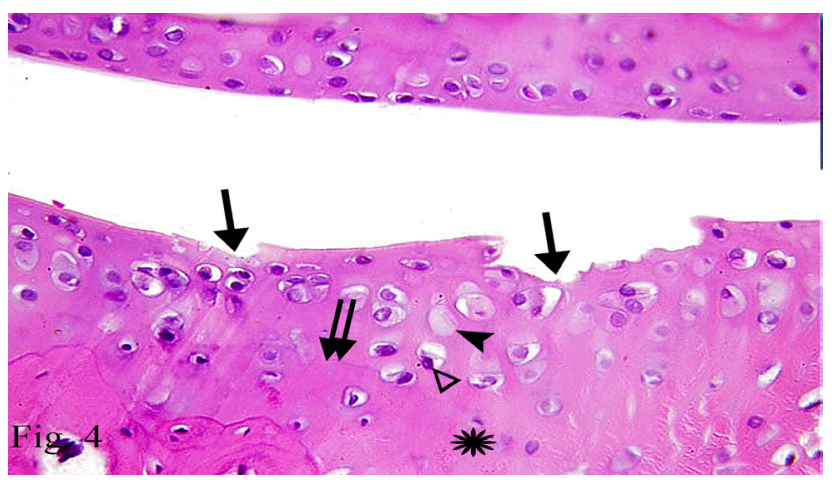

Fig. 4: Showing the articular cartilage with irregular surface and loss of its smooth contour $(\uparrow)$. Faint tidemark line $(\uparrow \uparrow)$ is seen in focal areas and absence of calcified cartilage $\left(^{*}\right)$ and tide marks are noticed in other focal areas. Empty chondrocyte lacuna $(\boldsymbol{\Delta})$ and chondrocytes with pyknotic nuclei $(\Delta)$ can also be noticed.

(Subgroup IIa) H\&E X400 


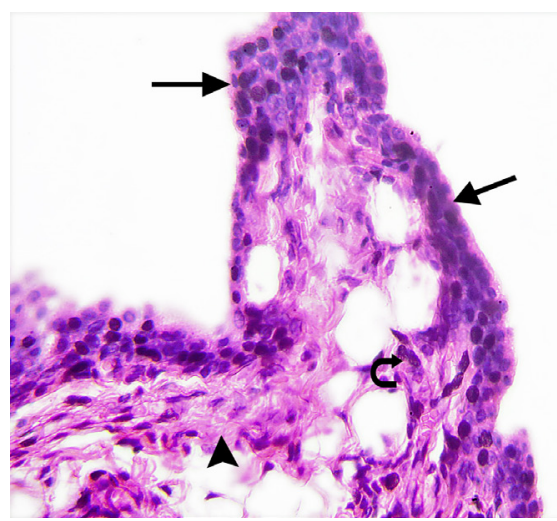

Fig. 5

Fig. 5: Showing the synovial mebrane with apparent increase in the number of macrophage-like synoviocyte type A $(\uparrow)$ and mononuclear cellular aggregations (curved arrow). Notice apparent increase in the collagen fibers between the adipocytes in the stroma $(\boldsymbol{\Delta})$.

(Subgroup IIa) H\&E X400

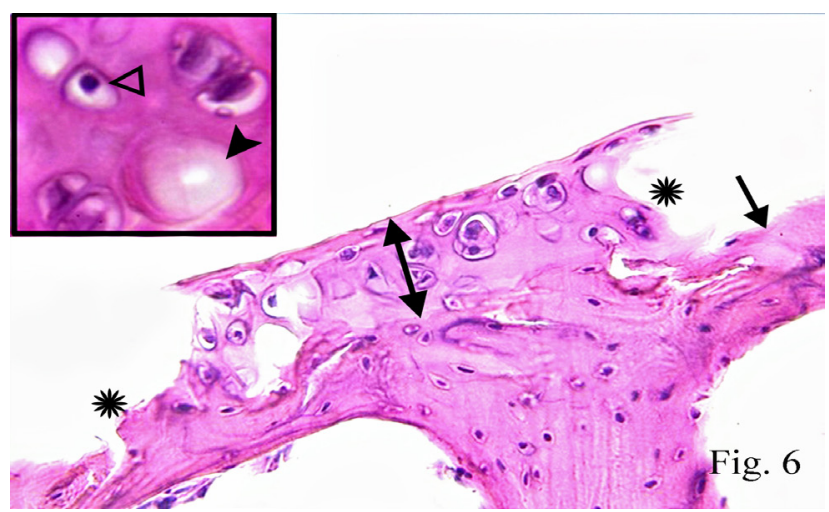

Fig. 6: Showing focal destruction of the articular cartilage $(*)$. Apparent decrease thickness of the cartilage $(\uparrow)$ with loss of basophilia and tidemark. Notice focal areas with destruction of the underlying bone $(\uparrow)$. Inset: shows degenerated chondrocytes with pyknotic nuclei $(\Delta)$ and empty lacuna $(\boldsymbol{\Lambda})$.

(Subgroup IIb) H\&E X400 Inset X1000

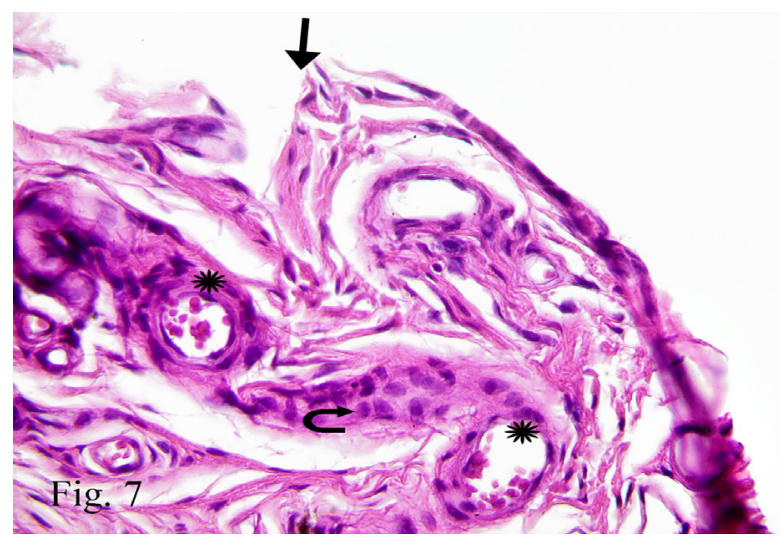

Fig. 7: Showing focal disruption of the cells lining the intima $(\uparrow)$ of the synovial membrane. Mononuclear cellular infiltration (curved arrow) is noticed between dilated congested blood vessels in the stroma $(*)$

(Subgroup IIb) H\&E X400

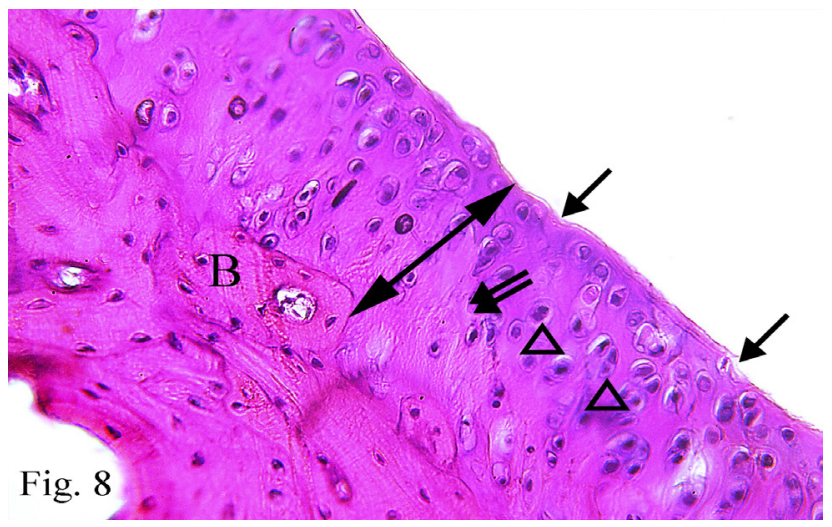

Fig. 8: Showing the articular cartilage with its four zones, subchondral bone (B) and tidemark line $(\uparrow \uparrow)$. Notice an apparent increase in the thickness of the cartilage $(\uparrow)$. The articular cartilage appears with slight irregularity of the surface $(\uparrow)$, but with preserved basophilic matrix and chondrocytes inside their lacunae $(\Delta)$.

(Group III) H\&E X400

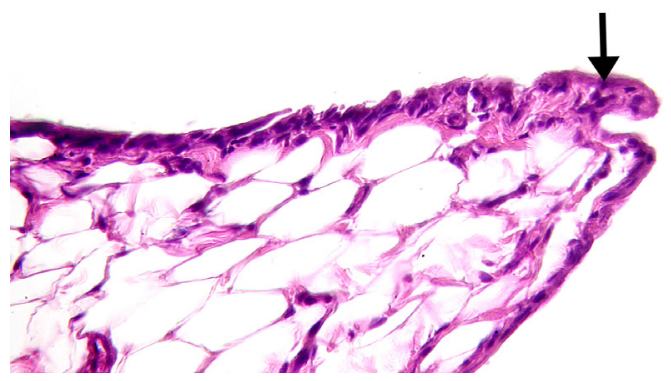

Fig. 9

Fig. 9: Showing mild increase in the intimal thickness $(\uparrow)$ of the synovial membrane.

(Group III) H\&E X400

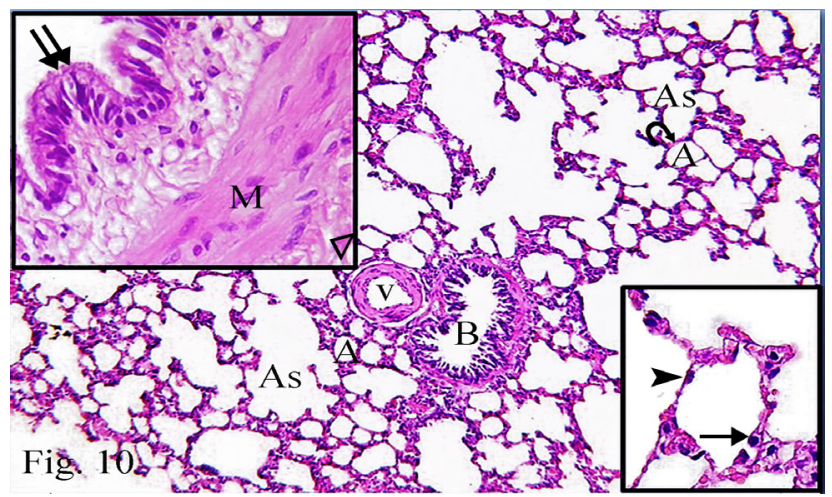

Fig. 10: Showing alveoli (A), alveolar sacs (As) separated by thin interalveolar septa (curved arrow). A bronchus (B) with a nearby blood vessel (V) can be seen. Left Inset: a part of bronchus lined by pseudostratified columnar epithelium $(\uparrow \uparrow)$, muscle layer (M) and adventitia $(\Delta)$. Right Inset: the alveoli are lined with type I pneumocytes with flat nuclei $(\mathbf{\Lambda})$ and cuboidal type II pneumocyte $(\uparrow)$.

(Group I) H\&E X100 Left and right insets X 400 


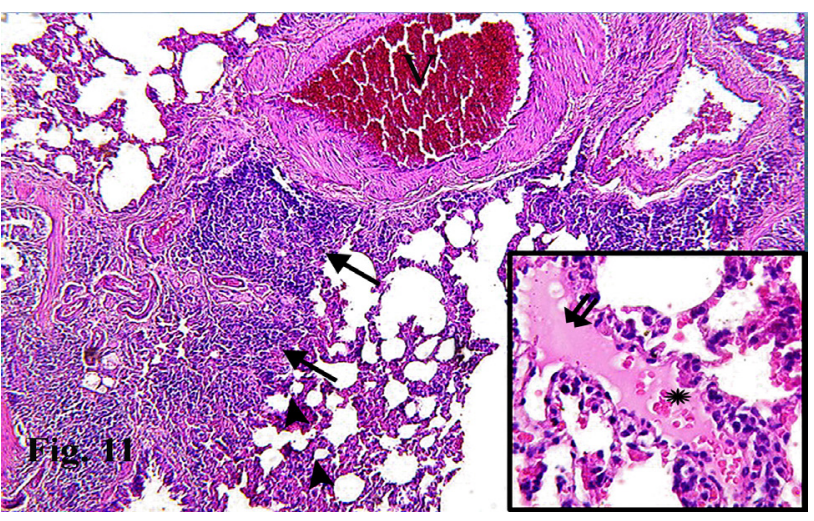

Fig. 11: Showing inflammatory cellular infiltration $(\uparrow)$ in the lung interstitium. Narrowed alveoli $(\boldsymbol{\Delta})$ and congested thickened blood vessels $(\mathrm{V})$ can be seen. Inset shows eosinophilic exudate $(\uparrow \uparrow)$ and extravasations of red blood cells $(*)$ in inter-alveolar septa.

(Subgroup IIa) H\&E X100

Inset X400

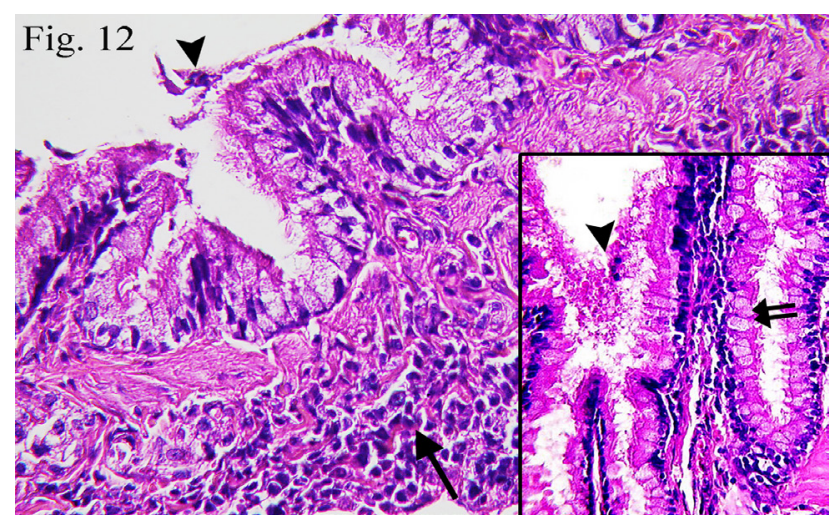

Fig. 12: Showing inflammatory cellular infiltration surrounding a bronchus $(\uparrow)$. Cellular debris $(\boldsymbol{\Lambda})$ can also be seen in its lumen. Inset: Numerous Goblet cells lining the bronchus $(\uparrow \uparrow)$ and cellular debris in the lumen $(\boldsymbol{A})$.

(Subgroup IIa) H\&E X400 Inset X400

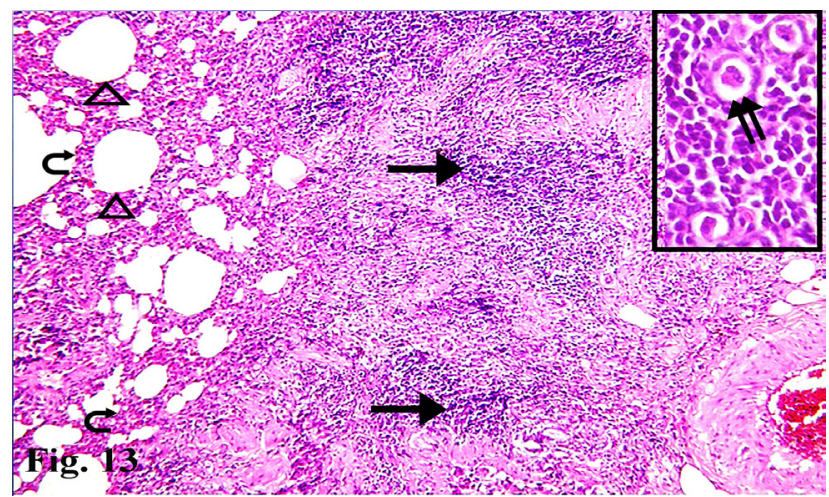

Fig. 13: Showing thickening of inter-alveolar septa (curved arrow), with obliteration of most alveoli and dilatation of others $(\Delta)$. Massive inflammatory cellular infiltration $(\uparrow)$ is seen in the interstitium. Inset: Many multinucleated giant cells $(\uparrow \uparrow)$ are noticed in the interstitium.

(Subgroup IIb) H\&E X100

Inset X 400

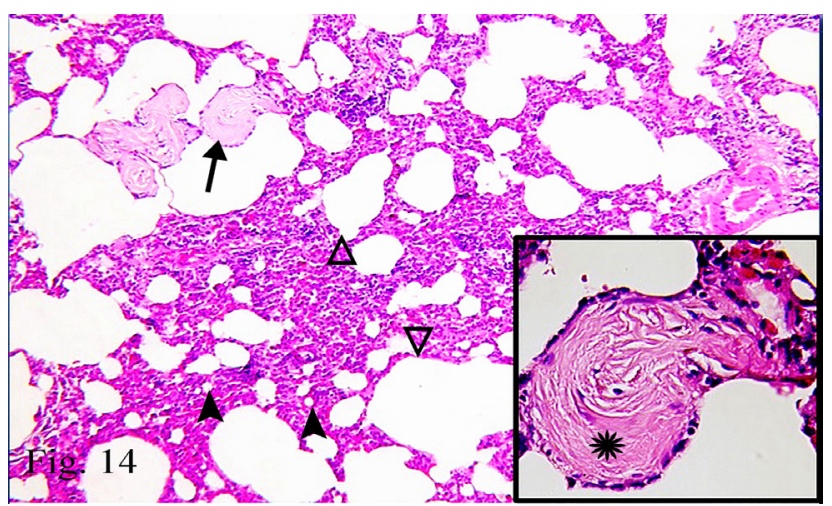

Fig. 14: Showing narrowing of some alveoli $(\Delta)$ and dilatation of others $(\Delta)$. Notice acidophilic material $(\uparrow)$ in the lung interstitium. Inset higher magnification showing whorly cellular acidophilic plugs $\left(^{*}\right)$.

(Subgroup IIb) H\&E X100 Inset X 400

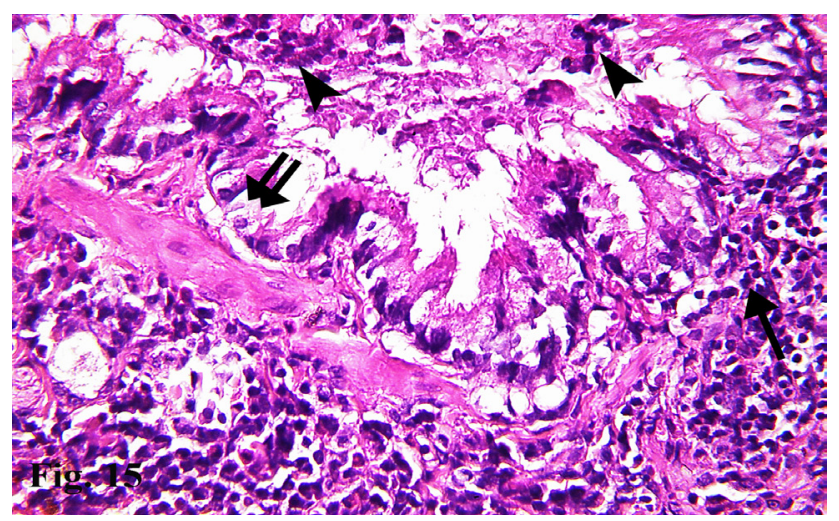

Fig. 15: Showing bronchus with areas of partial loss of the epithelial lining ( $\uparrow)$. The wall is heavily infiltrated with inflammatory cells $(\uparrow)$. Cellular debris and inflammatory cells ( $\Delta$ ) can be seen in the lumen of the bronchus.

(Subgroup IIb) H\&E X400

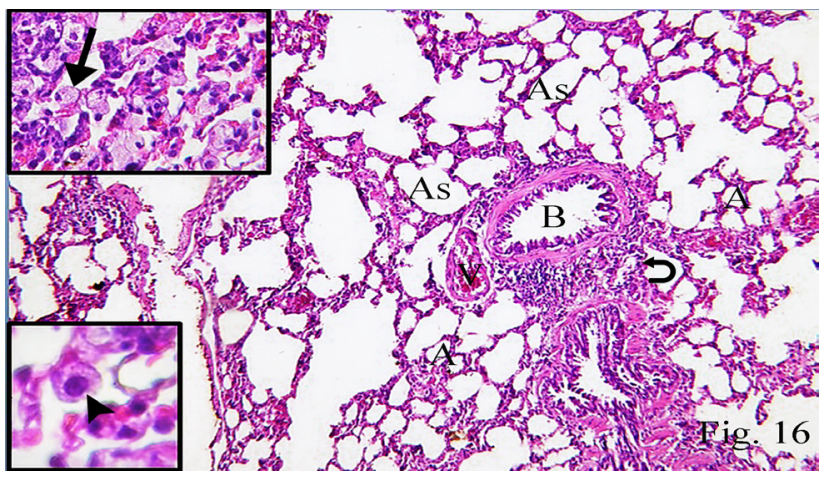

Fig. 16: Showing alveoli (A), alveolar sacs (As), bronchus (B) and blood vessels $(\mathrm{V})$. Notice focal areas of thickened interalveolar septa with inflammatory cellular infiltration (curved arrow). Upper inset shows apparent increase of the number of pneumocyte type II ( $\uparrow$ ) lining the alveoli. Lower inset shows cuboidal pneumocyte type II with rounded nucleus $(\boldsymbol{\Delta})$.

(Group III) H\&E X100 Upper insetX400 Lower inset X1000 


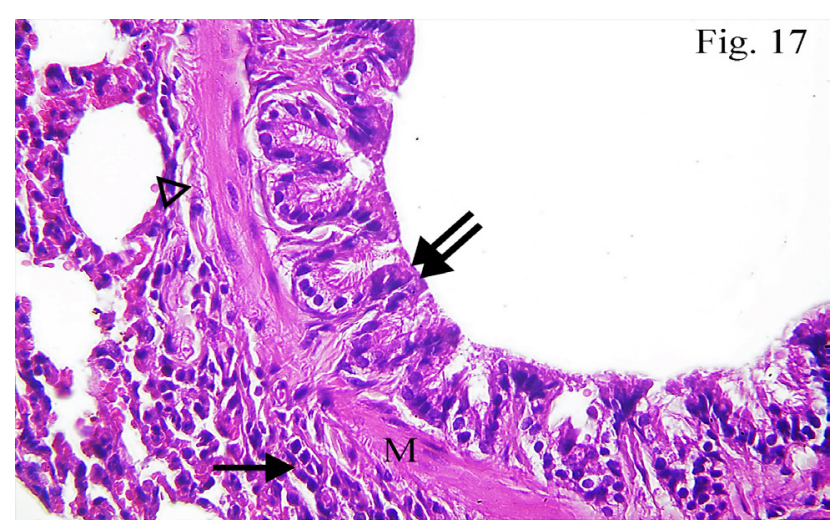

Fig. 17: Showing the lining epithelium of a bronchus $(\uparrow \uparrow)$, media (M) and adventitia $(\Delta)$. Few inflammatory cells $(\uparrow)$ are seen surrounding the bronchus.

(Group III) H\&E X400

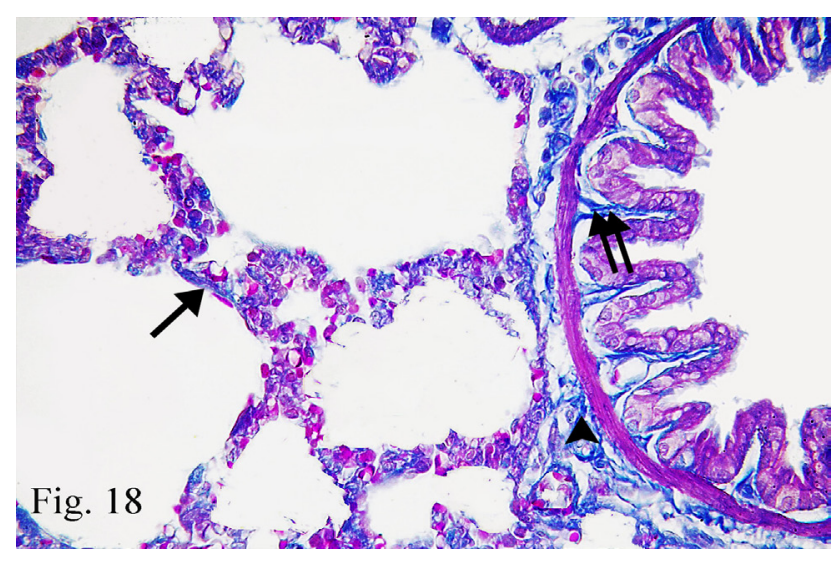

Fig. 18: Showing few collagen fibers in the interalveolar septa $(\uparrow)$, in the lamina propria $(\uparrow \uparrow)$ and adventitia $(\boldsymbol{\Delta})$ of the bronchus. (Group I) Mallory X400

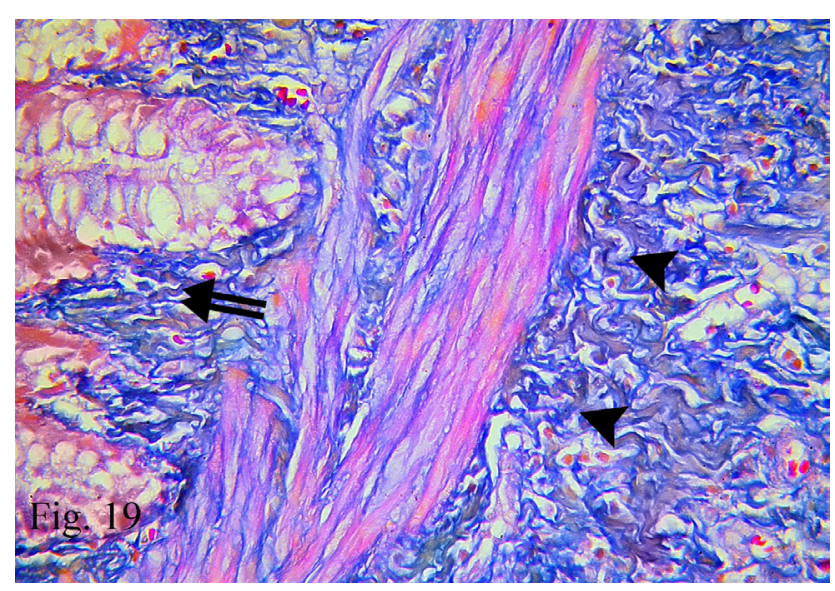

Fig. 19: Showing many collagen fibers in the lamina propria ( $\uparrow$ ) and around the wall of the bronchus $(\boldsymbol{\Delta})$.

(Subgroup IIa) Mallory X400

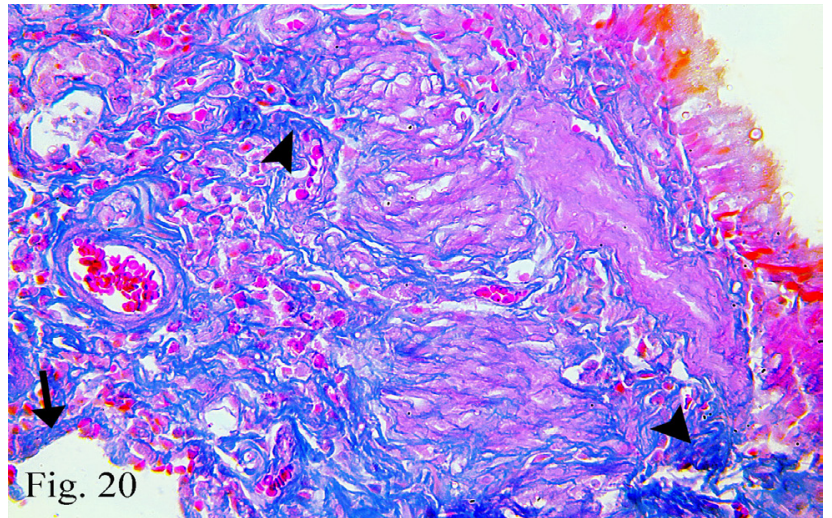

Fig. 20: Showing many collagen fibers in the interalveolar septa $(\uparrow)$, and around the wall of bronchus $(\boldsymbol{\Delta})$.

(Subgroup IIb) Mallory X400

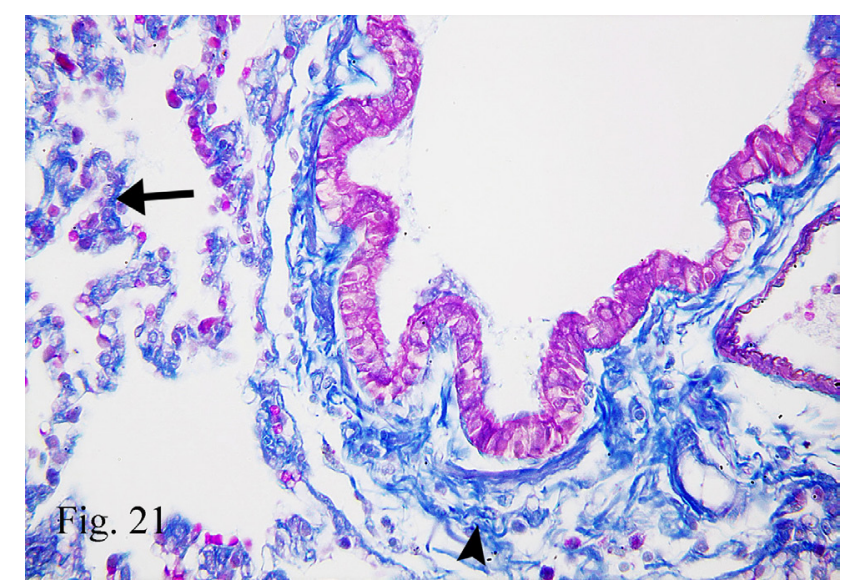

Fig. 21: Showing some collagen fibers in the interalveolar septa $(\uparrow)$ as well as around the wall of bronchus $(\boldsymbol{\Delta})$.

(Group III) Mallory X400

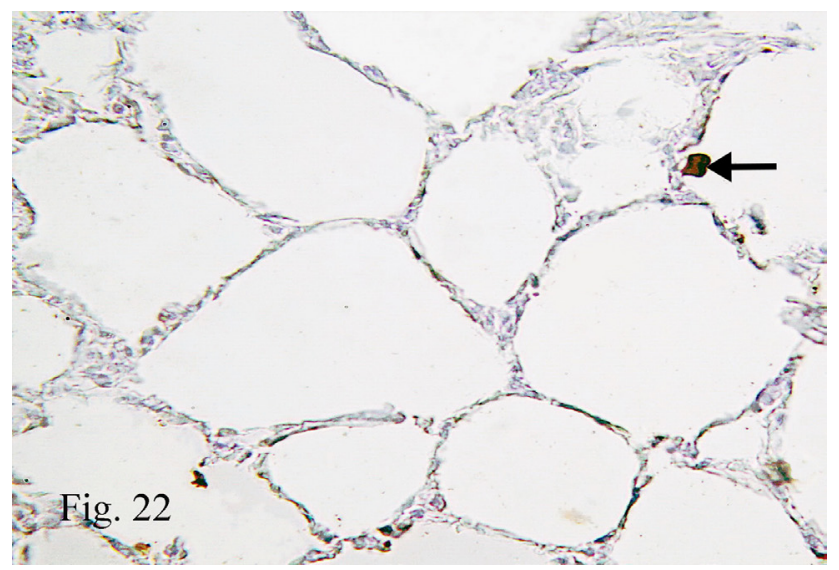

Fig. 22: Showing a cell $(\uparrow)$ with positive immune-histochemical reaction for TNF- $\alpha$ in the lumen of the alveoli. (Group I)

Avidin-biotin peroxidase for TNF- $\alpha$ X 400 


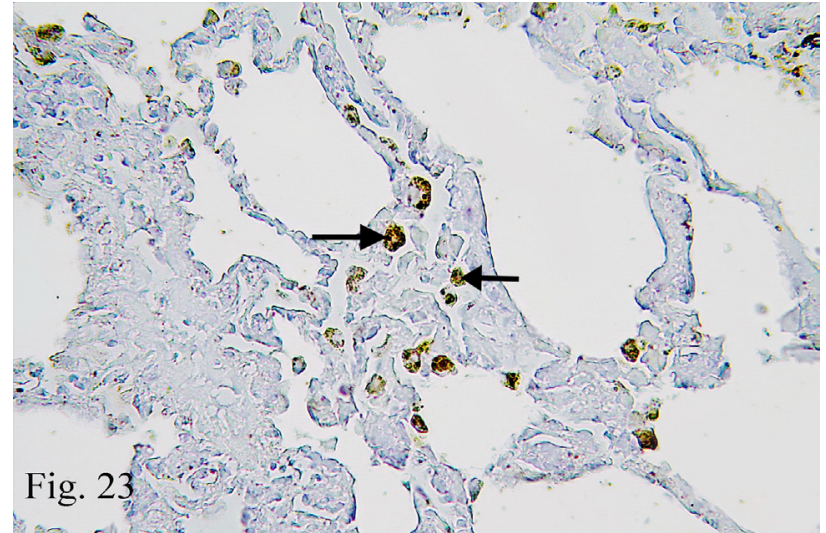

Fig. 23: Showing some cells $(\uparrow)$ with positive immunehistochemical reaction for TNF- $\alpha$ in inter-alveolar septa.

(Subgroup IIa)

Avidin-biotin peroxidase for TNF- $\alpha$ X 400

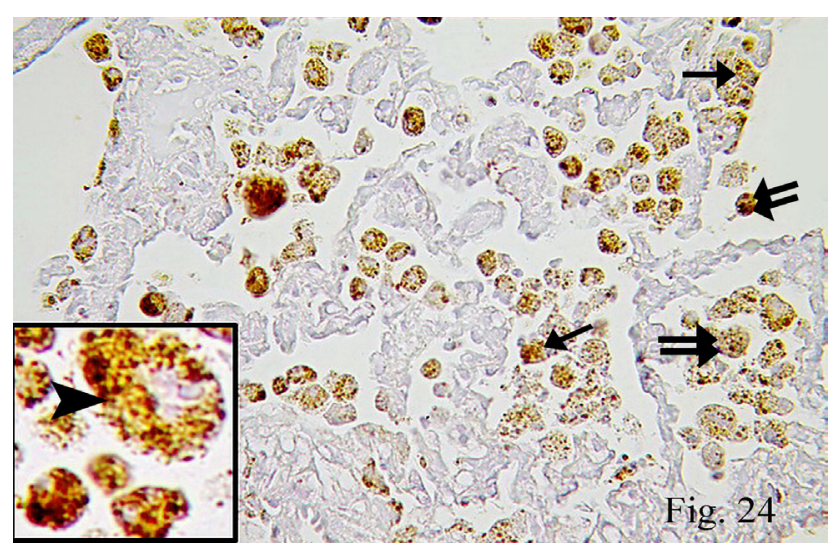

Fig. 24: Showing many cells with positive immune-histochemical reaction for TNF- $\alpha$ in inter-alveolar septa $(\uparrow)$ and in the lumen of alveoli $(\uparrow \uparrow)$. Inset: shows brownish granular cytoplasmic immune reaction in TNF- $\alpha$ positive cells $(\boldsymbol{\Delta})$

(Subgroup IIb)

Avidin-biotin peroxidase for TNF- $\alpha 400$ Inset X1000

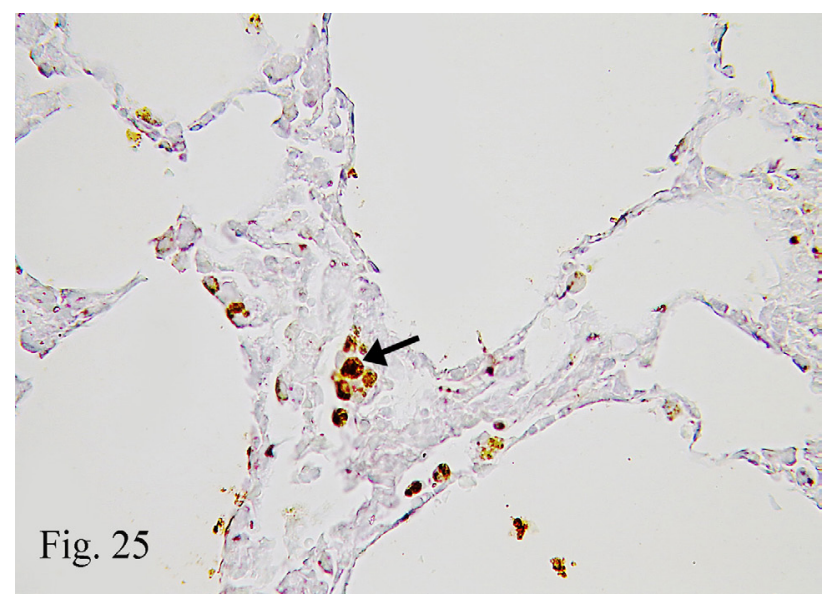

Fig. 25: Showing few cells $(\uparrow)$ with positive immunehistochemical reaction for TNF- $\alpha$ in inter-alveolar septa.

(Group III)

Avidin-biotin peroxidase for TNF- $\alpha$ X 400

\section{DISCUSSION}

Rheumatoid arthritis is a common severe systemic inflammatory disorder affecting all age groups. It commonly affects the joints, causing progressive, symmetric, erosive destruction of cartilage and bone, which is usually associated with autoantibody production ${ }^{[3]}$. Induction of autoimmune disease by Complete Freund's adjuvant (CFA) in rodents, gives a pathological picture closely related to that seen in RA patients. Furthermore, it is one of the standardized methods for induction of RA ${ }^{[8,18]}$. CFA is inactivated dried mycobacteria which is responsible for stimulation of cell-mediated immunity that ultimately increased the production of certain immunoglobulins ${ }^{[19]}$.

The adjuvant induced arthritis used in the current work showed some gross manifestations of RA as redness, swelling and limping in all paw joints. In addition, RA was confirmed histologically by light microscopic examination of ankle joints in subgroup IIa and progressed after four weeks of RA induction in subgroup IIb. This agreed with previous studies which established that RA developed after two weeks ${ }^{[20]}$ and progressed after four weeks of RA induction $^{[21,22]}$.

Faint tidemarks were noticed in the current study in group II. This might be due to impaired growth of cartilage. It was previously reported that turnover of articular cartilage occurs by replacement of calcified cartilage by bone. The calcified cartilage remains the same thickness throughout life as tidemark (calcification front) continues to advance into the noncalcified cartilage at a slow rate, which is in equilibrium with the rate of absorption of the calcified cartilage from the subarticular bone ${ }^{[23]}$.

In this work, effect of RA on the lung was evident by H\&E, Mallory's trichome and TNF- $\alpha$ examination. The findings were seen to be aggravated after four weeks of RA induction, which were correlated with our findings of ankle joint. In agreement, previous investigators linked RA to interstitial pulmonary diseases ${ }^{[24,25]}$. Interstitial lung disease was reported to be a common extra-articular manifestation of RA and was more likely to cause morbidity and mortality. In some cases, lung findings were noted prior to the onset of synovitis ${ }^{[22]}$.

Several mechanisms were implicated in the pathology of RA that might concurrently lead to joint and pulmonary structural changes. Initially, immune complex formation appeared to be a crucial step allowing access of autoantibodies to the synovium ${ }^{[26]}$. These blood-circulating immune complexes might lead to increased vascular permeability, allowing invasion of inflammatory cells into the joint tissue ${ }^{[27]}$. Moreover, immune complex deposition co-localizes with complement component, eventually resulted in ongoing synovitis ${ }^{[28]}$. Inflammation of both joints and lungs resulted from an overwhelming influx of mediators and activated immune cells generated by 
the systemic inflammatory reaction elicited by CFA. The role of CFA in experimental protocols of auto-immunity depends not only on potentiating formation of autoantibody and specific T-cell immunity, but also on creating a systemic and local inflammatory background allowing for specific immunity to focus on specific locations such as joints as well as lungs ${ }^{[5]}$.

Oxidative stress was implicated as a mechanism of RA by producing nitric oxide (NO) and inhibition of cell respiration. This inhibition might occur by binding of $\mathrm{NO}$ to cytochrome $\mathrm{C}$ oxidase leading to hypoxia. Hypoxia in turn induces angiogensis and production of pro-inflammatory cytokines $^{[29]}$. Proliferation of synoviocytes was noticed in the current study. It was reported synoviocytes proliferation was implicated in the pathogenesis of this damaging autoimmune chronic inflammatory disease ${ }^{[27]}$. Meanwhile, Inflammatory cells as polymorph nuclear leucocytes and macrophages can release a large amount of reactive oxygen species into the surrounding tissue, leading to impairment of structure of the cartilage ${ }^{[30]}$. In addition, it was demonstrated that in RA, macrophages, fibroblast-like synoviocytes and activated $\mathrm{T}$ cells produced pro-inflammatory mediators, as interleukin- 1 beta (IL-1 $\beta$ ) and TNF- $\alpha$, which played key roles in the pathogenesis of $\mathrm{RA}^{[31]}$. These cytokines might be involved in promoting inflammation, synovial tissue hyperplasia and osteoclast differentiation $^{[32]}$. Also, IL-1 $\beta$ and TNF- $\alpha$ might stimulate chondrocytes and osteoclasts to release the cartilage and bone-destroying metalloproteinase ${ }^{[33]}$. This might explain erosion and destruction of the articular cartilage and the underlying bone detected in the present study in both subgroups IIa and IIb, respectively.

In addition, IL-6 was reported to promote local leukocyte activation and autoantibody production. It was considered as an important mediator of the systemic effects of RA patients ${ }^{[34]}$. Furthermore, these inflammatory mediators also played a significant role in both the initiation and progression of pulmonary fibrosis as they released selected cytokines (IL-4, IL-13, and TGF- $\beta$ ), chemokines, and growth factors. These mediators promoted fibroblast differentiation and proliferation, providing a probable link between inflammation and fibrosis. At the same time, matrix metalloproteinases (MMPs) elaborated from damaged epithelia promoted activation of cytokines and pro-fibrotic mediators, contributing to the link between inflammatory cascades and tissue remodeling pathways. Angiogenesis also played a contributory role in this process, again with direct links to both inflammation and fibrosis ${ }^{[35]}$. These findings agreed with our results, as a significant increase in the mean area percentage of collagen fibers was noticed in lungs in both subgroups IIa and IIb. Furthermore, biopsy from patients with pulmonary fibrosis displayed elevated levels of TNF- $\alpha^{[7]}$, which, coincide with the significant increase in the number of positive TNF- $\alpha$ cell in both subgroups IIa and IIb. In the current study, the presence of
TNF- $\alpha$ in lung was an indicator of pulmonary inflammation and fibrosis.

In this work, increase number of goblet cells in the bronchi, obliteration of most alveoli and compensatory dilatation of others were noticed in focal areas in the lung of subgroup IIb. This could be explained by some authors who reported that inflammation of the bronchi might lead to increased mucus secretion (chronic bronchitis) and destruction of lung parenchyma with subsequent emphysema ${ }^{[36]}$. Additionally, whorly cellular acidophilic plugs were also noticed in pulmonary interstitium in our study in subgroup IIb. Some investigators explained that this pattern is considered a type of organized pneumonia that has been described as a manifestation of all connective tissue diseases including RA. They described this pattern as plugs of fibroblasts embedded in immature collagenous matrix within alveolar spaces or alveolar ducts ${ }^{[37]}$.

Administration of omega-3 fatty acid had a significant therapeutic effect on the structure of both ankle joint and lung consistent with previous studies whereas omega-3 supplementation in patients with RA resulted in a significant improvement in the clinical symptoms of RA and a decrease in NSAID requirements ${ }^{[10,38]}$.

Moreover, omega-3 has a strong anti-inflammatory effect ${ }^{[38]}$ and it also decreased proinflammatory cytokines including IL-1 $\beta$, IL- 6 and TNF- $\alpha$. In addition, omega-3 was found to produce immunomodulatory substances as prostaglandins, thromboxanes and leukotrienes through direct effects on their transcription regulation ${ }^{[39]}$. Other investigators attributed the anti-inflammatory action of omega-3 to their production of the lipid mediators resolvins and protectins ${ }^{[38]}$. Whereas, resolvin inhibited IL-1 $\beta$ production, reduced inflammation and protected experimental animals in models of inflammatory disease including arthritis. Similarly, protectin inhibited IL-1 $\beta$, and TNF- $\alpha$ production ${ }^{[40]}$. In context, a significant decrease in the number of cells with positive TNF- $\alpha$ immunehistochemical reaction was noticed in group III compared to subgroups IIa and IIb. Meanwhile, there was an apparent increase in the number of type- II pneumocyte in group III. This was explained by some investigators who reported that proliferation and hyperplasia of type-II pneumocytes was considered an important marker for restoration of both types of alveolar cells during lung injury and repair ${ }^{[41]}$.

The anti-fibrotic effect of omega-3 obtained in this work may be explained as omega-3 decreased MMPs and inhibited TGF- $\beta$-induced epithelial mesenchymal transition process $^{[39]}$.

\section{CONCLUSION}

RA has deleterious effects on ankle joint and caused structural damage to the lung. However, early omega-3 
administration ameliorates lung damage by exerting anti-inflammatory and antifibrotic effects. Consequently, omega- 3 could have potential therapeutic implications in early RA.

Further studies on the effects of omega-3 on other organs are recommended to fully clarify its potential therapeutic role in autoimmune diseases.

\section{CONCLICT OF INTEREST}

There are no conflicts of interest

\section{REFERENCES}

1. Soliman N. Effect of intra-articular injection of high-molecular-weight versus low-molecularweight hyaluronic acid on the articular cartilage structure in experimentally induced knee joint osteoarthritis in albino rats. Egypt. Journ. Histol. 2012, 35: 483-495.

2. Karmakar S, Kay j, Granellas EM. One damage in rheumatoid arthritis: mechanistic insight and approaches to prevention. Rheum Dis Clin North Am; 2010, 36: 385-404.

3. Alamanos Y, Drosos AA. Epidemiology of adult rheumatoid arthritis. Autoimmun Rev. 2005 Mar;4(3): 130-136.

4. Koo ST, Lee CH, Choi H, Shin YI, Ha KT, Ye $\mathrm{H}$, Shim HB. The effects of pressure on arthritic knees in a rat model of CFA-induced arthritis. Pain Physician. 2013 Mar-Apr; 16(2): E95-102.

5. Schurgers E, Mertens F, Vanoirbeek JA, Put S, Mitera T, De Langhe E, Billiau A, Hoet PH, Nemery B, Verbeken E, Matthys P. Pulmonary inflammation in mice with collagen-induced arthritis is conditioned by complete Freund's adjuvant and regulated by endogenous IFN- $\gamma$. Eur J Immunol. 2012 Dec; 42(12): 3223-34.

6. Anand AS, Joseph PB, Vera-Vazquez E. A case of pulmonary fibrosis associated with rheumatoid arthritis, scleroderma sine scleroderma and ANCA associated vasculitis. Springerplus. 2014 Sep 10; 3: 513.

7. Kayhan S, Guzel A, Duran L, Tutuncu S, Guzel A, Gunaydın M, Salis O, Okuyucu A, Selcuk MY. Effects of leflunomide on inflamation and fibrosis in bleomycine induced pulmonary fibrosis in wistar albino rats. $\mathrm{J}$ Thorac Dis. 2013 Oct; 5(5): 641-9.

8. Suke SG, Negi H, Mediratta PK, Banerjee BD,
Sharma KK. Anti-arthritic and anti-inflammatory activity of combined pioglitazone and prednisolone on adjuvant-induced arthritis. Eur J Pharmacol. 2013 Oct $15 ; 718(1-3): 57-62$.

9. Chen JS, Hill CL, Lester S, Ruediger CD, Battersby R, Jones G, Cleland LG, March LM. Supplementation with omega-3 fish oil has no effect on bone mineral density in adults with knee osteoarthritis: a 2-year randomized controlled trial. Osteoporos Int. 2016 May; 27(5): 1897-1905.

10. Park Y, Lee A, Shim SC, Lee JH, Choe JY, Ahn H, Choi CB, Sung YK, Bae SC. Effect of n-3 polyunsaturated fatty acid supplementation in patients with rheumatoid arthritis: a 16-week randomized, double-blind, placebo-controlled, parallel-design multicenter study in Korea. J Nutr Biochem. 2013 Jul; 24(7): 1367-72.

11. Makhlouf NA, Khalil WF and Farghaly LM. The possible therapeutic effect of 'Chaetomium globosum' fungal extract on experimentally induced rheumatoid arthritis. Egypt. J. Histol. 2013, 36: 964-978.

12. Caron MF and White CM. Evaluation of the antihyperlipidemic properties of dietary supplements. Pharmacotherapy 2001, Apr; 21(4): 481-487.

13. Soliman N, Kalleny NK and Abd El Samad AA. Effect of Omega-3 Versus Omega-6 Fatty Acids on Induced Ulcerative Colitis in Male Albino Rat. Light and Electron Microscopic Study. Egypt. J. Histol. 2010, Dec; 33(4): 620 - 634.

14. Barsante MM, Roffê E, Yokoro CM, Tafuri WL, Souza DG, Pinho V. Anti-inflammatory and analgesic effects of atorvastatin in a rat model of adjuvant induced arthritis. Eur J Pharmacol 2005; 516: 282-289.

15. United States Department of Agriculture. USDA National Nutrient Database for Standard Reference, Release 22. 2009; Available at: http:// www.data.gov/raw/1458.

16. Suvarna K, Layton C, Bancroft J. Theory and practice of histological techniques. 7th ed. USA: Churchill Livingston; 2013; 203:500.

17. Scudamore CL. A practical guide to the histology of the mouse. 1st edition. Wiley Blackwell. John Wiley and Sons, Ltd.Laserwords private, Chennai, India, 2014. p:17-18.

18. Torres-Guzman AM, Morado-Urbina CE, 
Alvarado-Vazquez PA, Acosta-Gonzalez RI, Chávez-Piña AE, Montiel-Ruiz RM, JimenezAndrade JM. Chronic oral or intraarticular administration of docosahexaenoic acid reduces nociception and knee edema and improves functional outcomes in a mouse model of Complete Freund's Adjuvant-induced knee arthritis. Arthritis Res Ther. 2014 Mar 10; 16(2): R64.

19. Billiau A, Matthys P. Modes of action of Freund's adjuvants in experimental models of autoimmune diseases. J. Keukoc. Biol 2001; 70: 849-860.

20. Safonova OA, Popova TN, Kryl'skii ED, Tanygina ES, Kirilova EM. Synthesis and estimation of the Influence of 2,4-Dimethoxyphenylbiguanide on the Glutathione antioxidant system activity in heart and blood serum of rats with experimental rheumatoid arthritis. Pharmaceutical Chemistry Journal 2016; 49(11): 749-752.

21. Bader AA. Synergistic Ameliorative Effects of Resveratrol with Leflunomide On Serum Levels of Inflammatory Biomarkers and Joint Damage in Rats with Adjuvant Arthritis International Journal of Pharmacology and Toxicology 2015; 5(2): 94-103.

22. Demoruelle MK, Deane KD, Holers VM. When and where does inflammation begin in rheumatoid arthritis?. Curr Opin Rheumatol. 2014 Jan; 26 (1): 64-71.

23. Mills SE. Histology for pathologists. 4th ed. Lippincott Williams \& Wilkins. Wolters Kluwer, Business Philadelphia, PA 19103 USA 20121; p: 125-145

24. Shaw M, Collins BF, Ho LA, Raghu G. Rheumatoid arthritis-associated lung disease. Eur Respir Rev. 2015 Mar; 24 (135): 1-16.

25. Giles JT, Danoff SK, Sokolove J, Wagner CA, Winchester R, Pappas DA, Siegelman S, Connors G, Robinson WH, Bathon JM. Association of fine specificity and repertoire expansion of anticitrullinated peptide antibodies with rheumatoid arthritis associated interstitial lung disease. Ann Rheum Dis. 2014 Aug; 73(8): 1487-94.

26. Binstadt BA, Patel PR, Alencar H, Nigrovic PA, Lee DM, Mahmood U, Weissleder R, Mathis D, Benoist C. Particularities of the vasculature can promote the organ specificity of autoimmune attack. Nat Immunol. 2006; 7(3): 284-92.
27. Hitchon CA, El-Gabalawy HS. The Synovium in Rheumatoid Arthritis. The Open Rheumatology Journal 2011; 5 (Suppl 1:M3): 107-114.

28. Zhao X, Okeke NL, Sharpe O, Batliwalla FM, Lee AT, Ho PP, Tomooka BH, Gregersen PK, Robinson WH. Circulating immune complexes contain citrullinated fibrinogen in rheumatoid arthritis. Arthritis Res Ther. 2008; 10(4): R94.

29. Bao F, Wu P, Xiao N, Qiu F, Zeng QP. Nitric oxidedriven hypoxia initiates synovial angiogenesis, hyperplasia and inflammatory lesions in mice. PLoS One 2012; 7:e34494.

30. Bauerova K, Paulovicova E, Mihalova D, Drafi F, Strosova M, Mascia C, Biasi F , Rovensky J , Kucharska J, Gvozdjakova A, Ponist S. Combined methotrexate and coenzyme Q10 therapy in adjuvant-induced arthritis evaluated using parameters of inflammation and oxidative stress. Acta Biochim Pol 2010; 57: 347-354.

31. Haynes DR. Inflammatory cells and bone loss in rheumatoid arthritis. Arthritis Res Ther 2007; 9: 104.

32. Ali AA, El-Zaitony AS, Al-Haleem ENA Evaluation of Therapeutic Efficacy of Vinpocetine in Adjuvant Induced Arthritis Model in Rats. J Pain Manage Med, 2016; 2(3): 115-125.

33. Gravallese EM. Bone destruction in arthritis. Ann Rheum Dis 2002; 61: 84-86.

34. McInnes IB, Schett G. The pathogenesis of rheumatoid arthritis. The New England journal of medicine, 2011; 365: 2205-2219.

35. Brito Y, Glassberg MK, Ascherman DP. Rheumatoid Arthritis-Associated Interstitial Lung Disease: Current Concepts. Curr Rheumatol Rep. 2017 Nov 9; 19(12): 79.

36. Bongartz $T$, Nannini $C$, Medina-Velasquez YF, Achenbach SJ, Crowson CS, Ryu JH, Vassallo R, Gabriel SE, Matteson EL. Incidence and mortality of interstitial lung disease in rheumatoid arthritis: a population-based study. Arthritis Rheum. 2010; 62(6):1583-91.

37. Hozumi H, Nakamura Y, Johkoh T, Sumikawa $\mathrm{H}$, Colby TV, Kono M, Hashimoto D, Enomoto N, Fujisawa T, Inui N, Suda T, Chida K. Acute exacerbation in rheumatoid arthritis-associated interstitial lung disease: a 
retrospective case control study. BMJ Open. 2013 Sep 13; 3(9): e003132.

38. Calder PC. Omega-3 polyunsaturated fatty acids and inflammatory process: nutrition of pharmacology. $\mathrm{Br} \mathrm{J}$ Clin Pharmacol 2012; 75 (3): 645-662.

39. Pastor-Clerigues A, Marti-Bonmati E, Milara J, Almudever P, Cortijo J. Anti-Inflammatory and Anti-Fibrotic Profile of Fish Oil Emulsions Used in Parenteral Nutrition-Associated Liver Disease. PLOS ONE, 2014; 12: 1-25.
40. Lima-Garcia JF, Dutra RC, da Silva K, Motta EM, Campos MM, Calixto JB. The precursor of resolvin $\mathrm{D}$ series and aspirin-triggered resolvin D1 display anti-hyperalgesic properties in adjuvant-induced arthritis in rats. Br $\mathrm{J}$ Pharmacol 2011; 164: 278-93.

41. Feng D, Zhang S, Hu Z, Fan F, Jiang F, Yin R, Xu L. Dynamic investigation of alveolar type II cell function in a long-term survival model of rat lung ischemia- reperfusion injury. Scand J Clin Lab Invest 2010; 70: 364-373. 
الملخص العربى

\section{تقييم الدور العلاجي المحتمل للأوميغا3- على بنية الكاحل والرئة في نموذج التهاب المفاصل

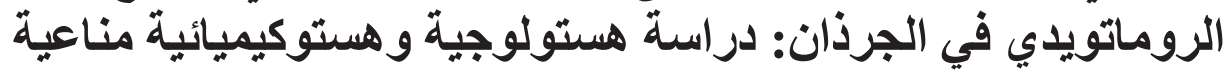

\section{مني حسين رأفت1، غادة جلال حمام1، مها فرحان، لورا صباغ²، نور عبدالايم² وعبدالغني شرف2

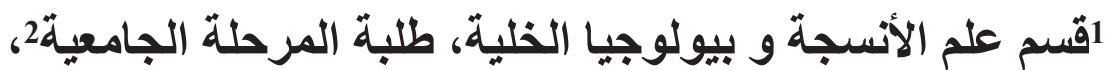 \\ كلية الطب، جامعة عين شمس، القاهرة، مصر}

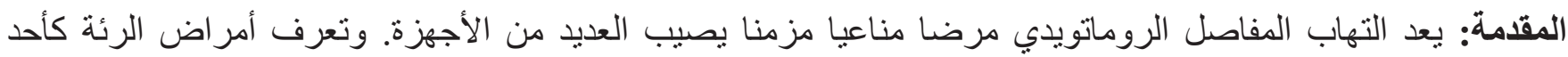
المضاعفات الثائعة لمرض التهاب المفاصل الروماتويدي. كما يعد الأوميغا3- من الأحماض الدهنية الأساسية التي لها تأثير الثير

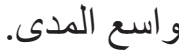
الهدف من البحث: در اسة الدور العلاجي المحتمل للحمض الدهني الحر أوميغا3- على بنية الكاحل والرئة في نموذج التهاب

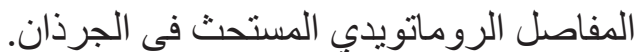

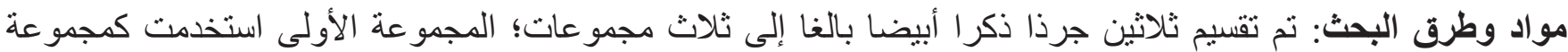

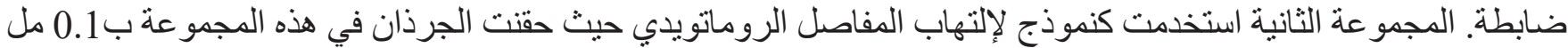

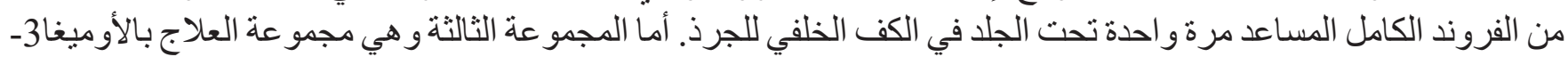

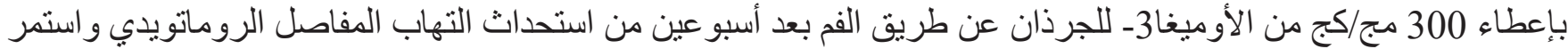

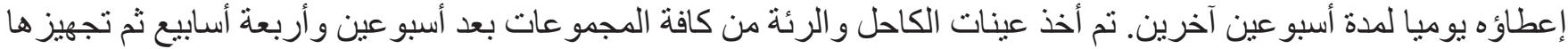

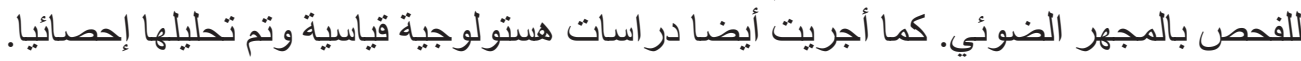

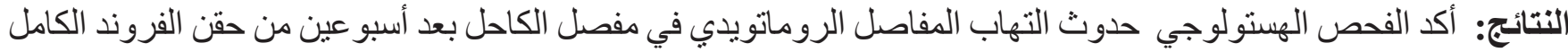

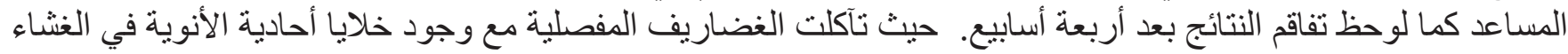

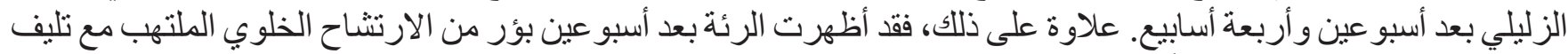

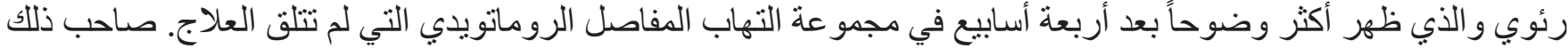

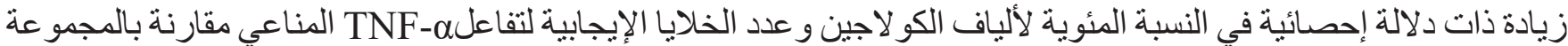

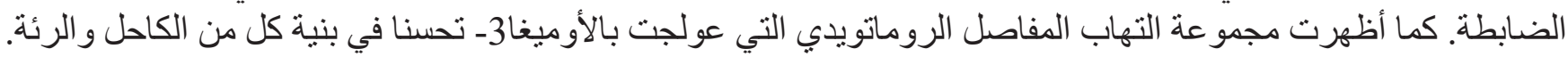
الإستتتاج: أدى استخدام الأوميغا3- إلى تحسن ذي دلالة إحصائية في الأضر ار التركيبية للكاحل و الرئة بعد استحداث التهاب المفاصل الروماتو يدي. 